Wright State University

CORE Scholar

6-1-2012

\title{
New Primers Reveal the Presence of a Duplicate Histone H3 in the Marine Turtle Leech Ozobranchus branchiatus
}

Triet Minh Truong

Wright State University - Main Campus

Audrey E. McGowin Ph.D.

Wright State University - Main Campus, audrey.mcgowin@wright.edu

Philip Lavretsky

Jeffrey L. Peters Ph.D.

Wright State University - Main Campus, jeffrey.peters@wright.edu

Follow this and additional works at: https://corescholar.libraries.wright.edu/chem_student

Part of the Chemistry Commons

\section{Repository Citation}

Truong, T. M., McGowin, A. E., Lavretsky, P., \& Peters, J. L. (2012). New Primers Reveal the Presence of a Duplicate Histone $\mathrm{H} 3$ in the Marine Turtle Leech Ozobranchus branchiatus. .

https://corescholar.libraries.wright.edu/chem_student/6

This Presentation is brought to you for free and open access by the Chemistry at CORE Scholar. It has been accepted for inclusion in Chemistry Student Publications by an authorized administrator of CORE Scholar. For more information, please contact library-corescholar@wright.edu. 


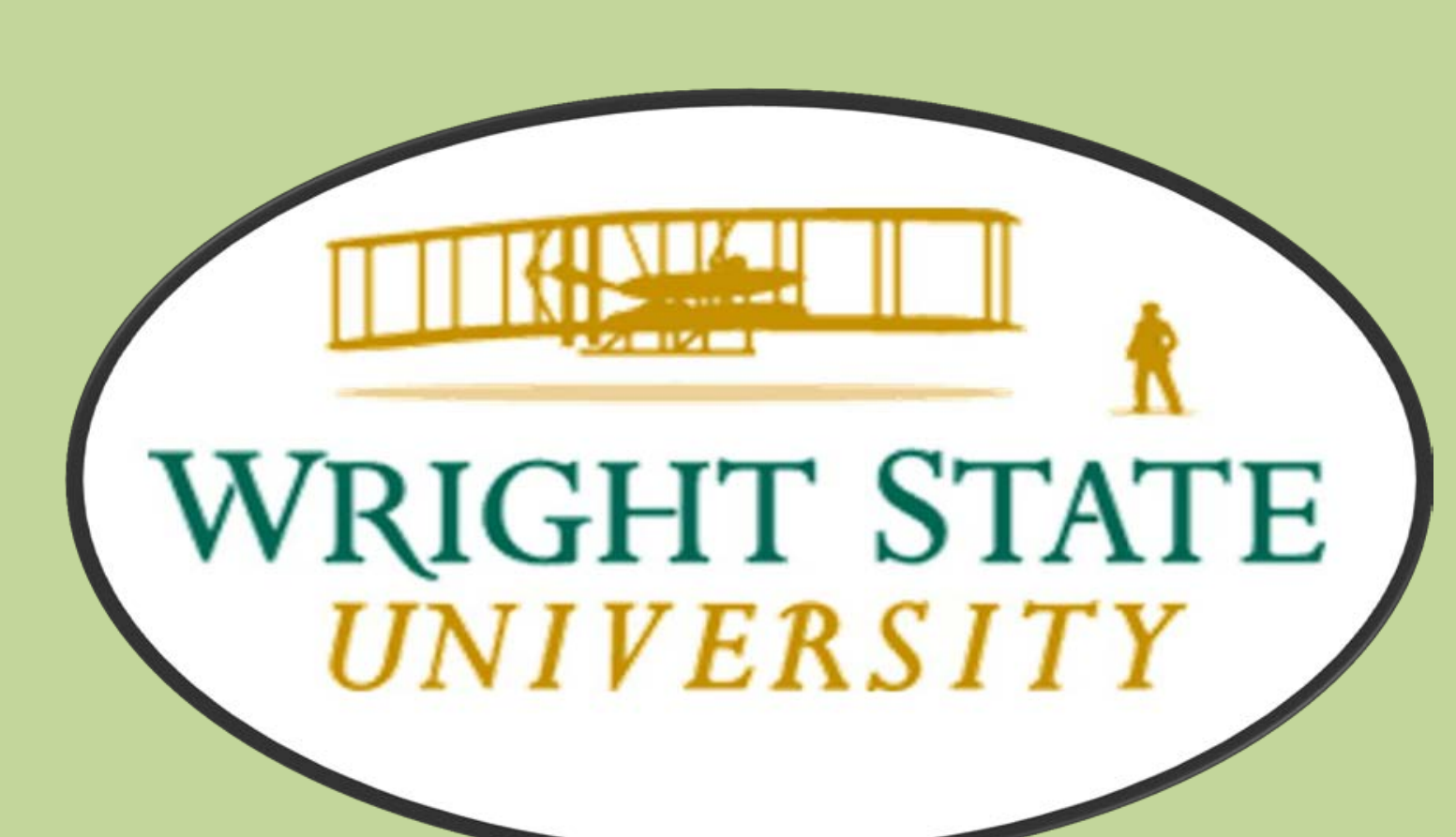

New primers reveal the presence of a duplicate histone $\mathrm{H} 3$ in the marine turtle leech Ozobranchus branchiatus
Triet M. Truong and Audrey E. McGowin, Ph.D. Department of Chemistry
Philip Lavretsky and Jeffrey L Peters, PhD Department of Biological Sciences क्डs:
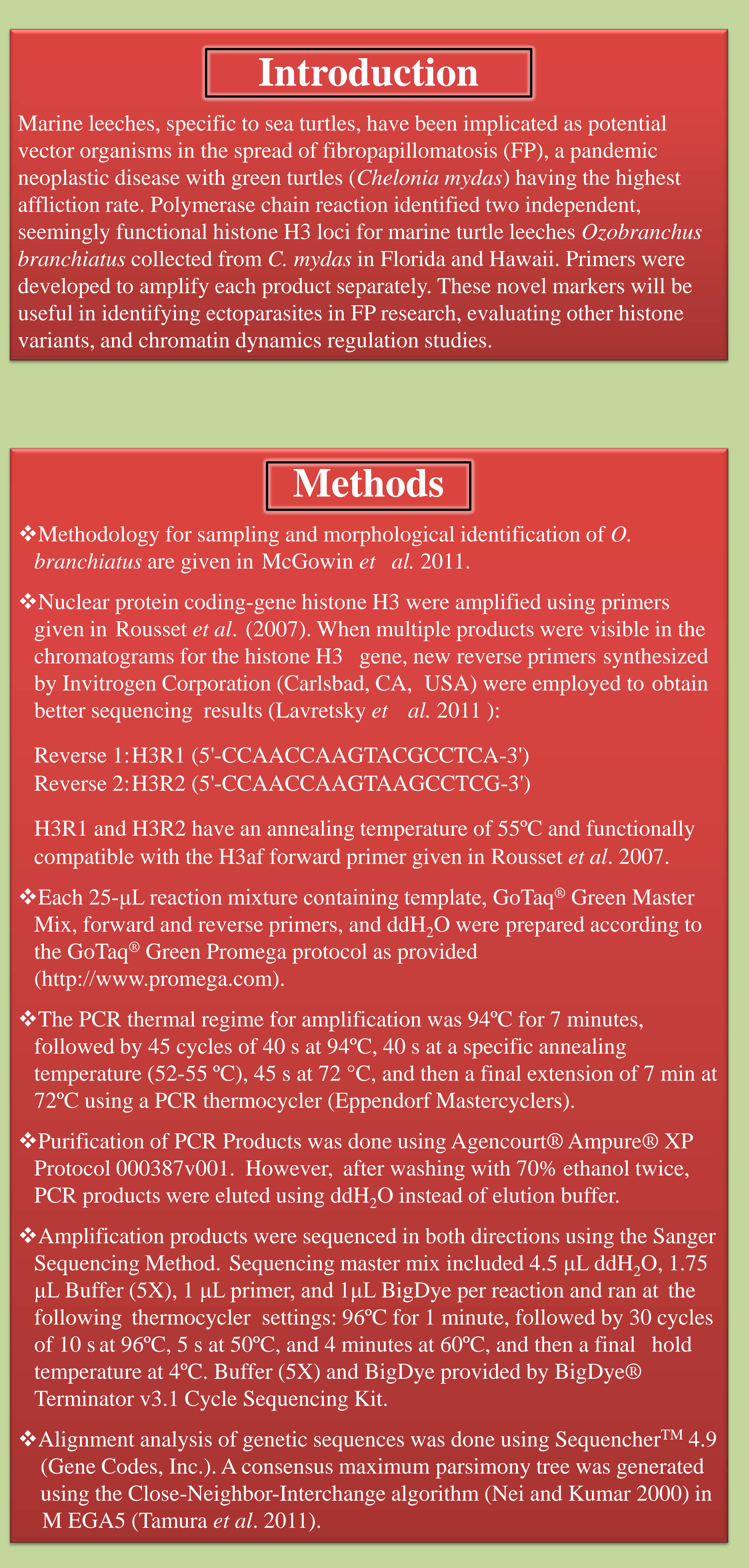

References

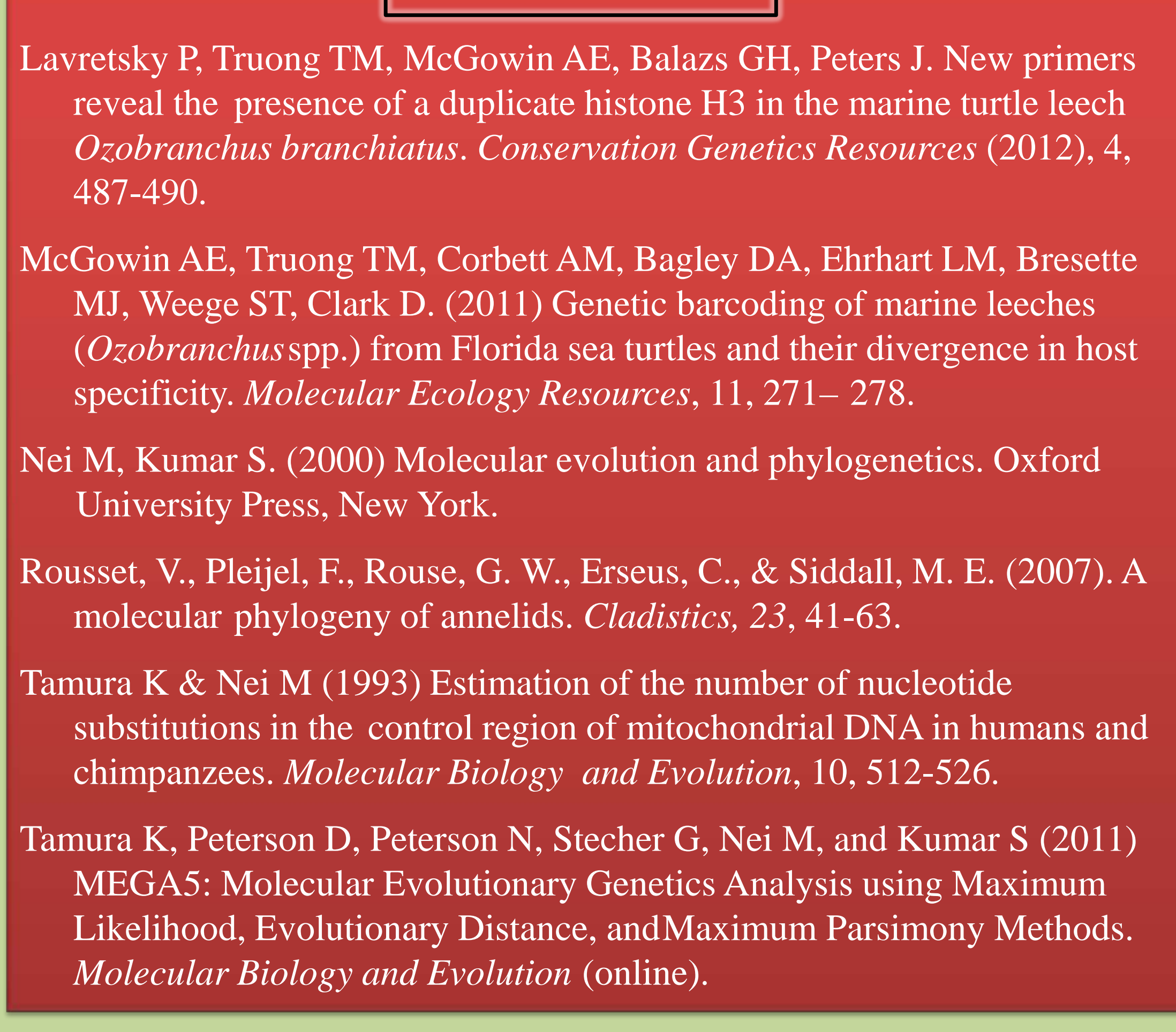

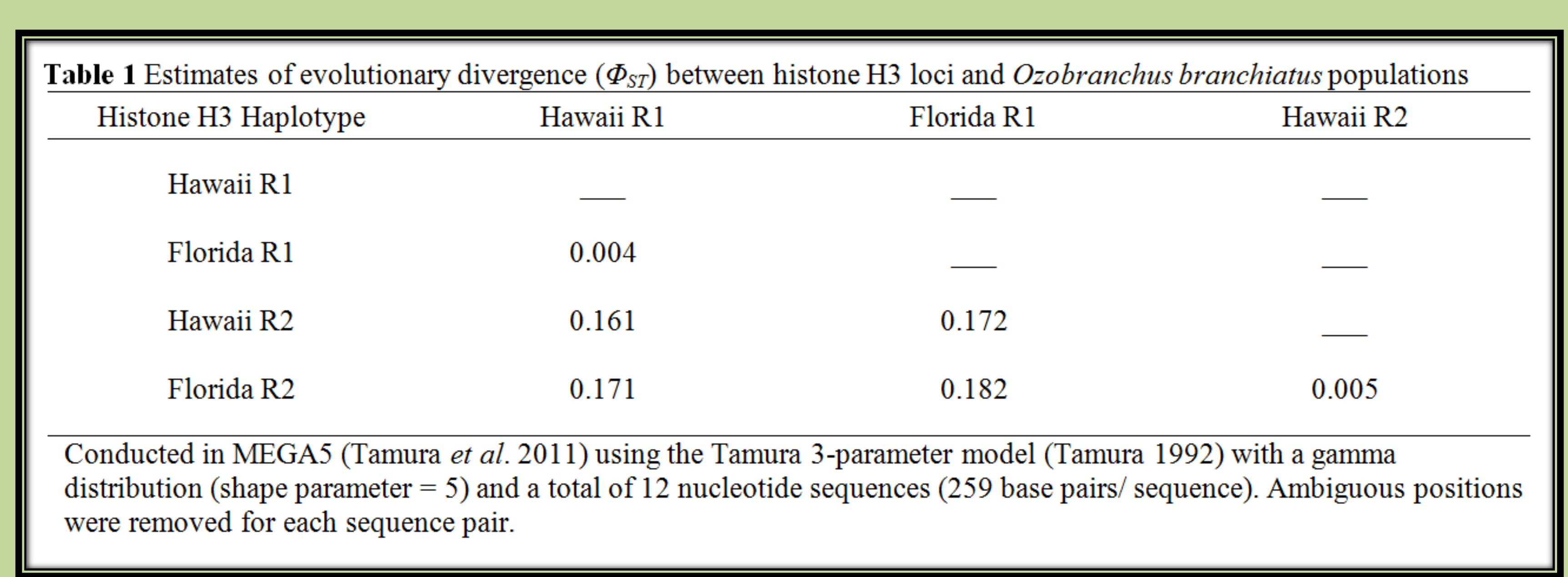

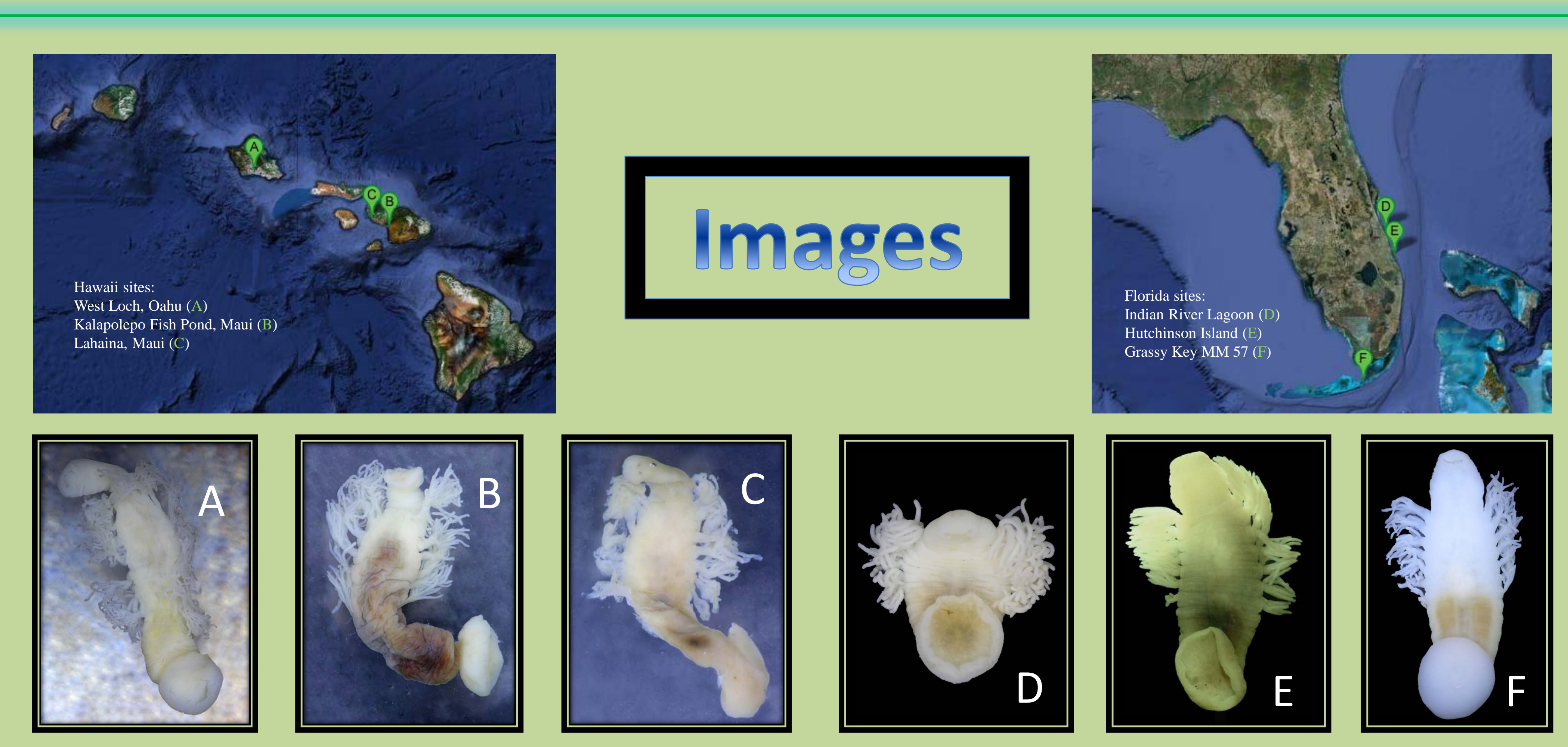

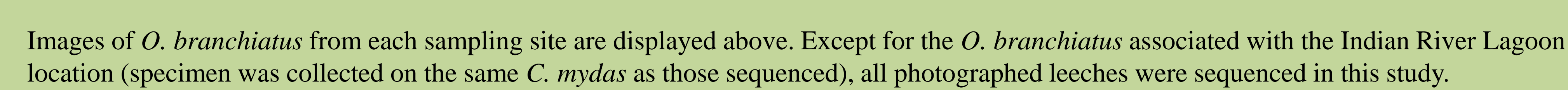

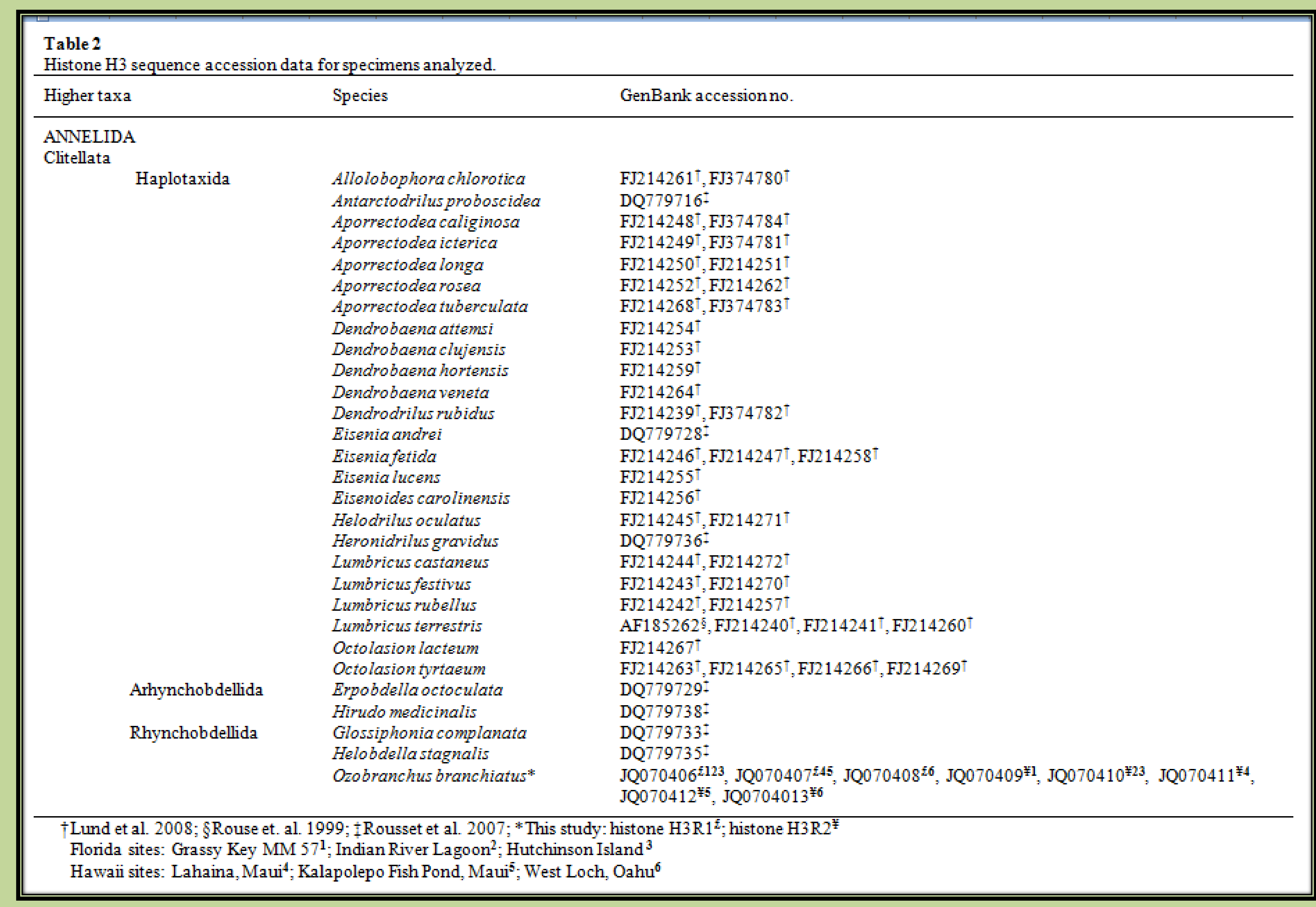

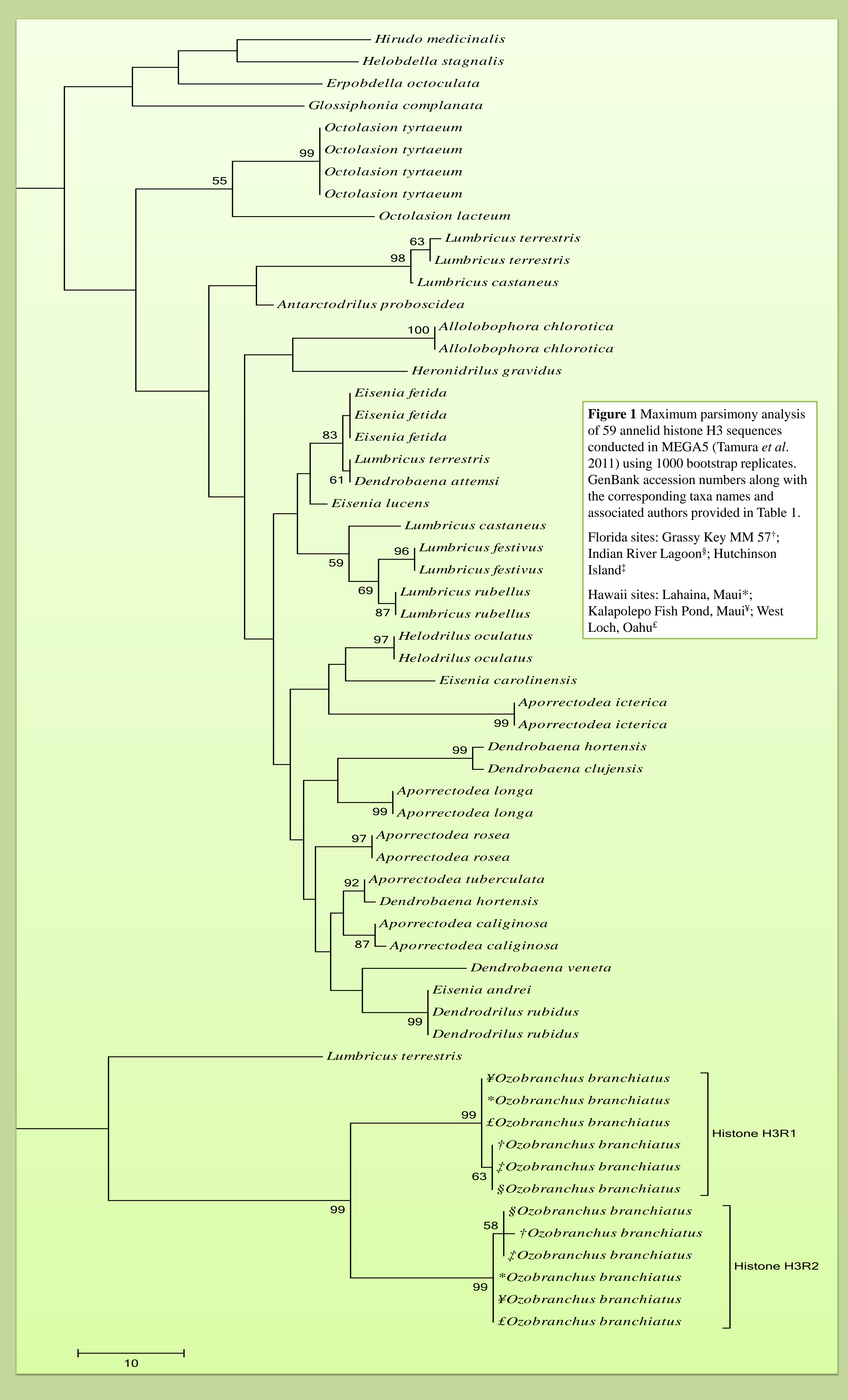

Results and Conclusions

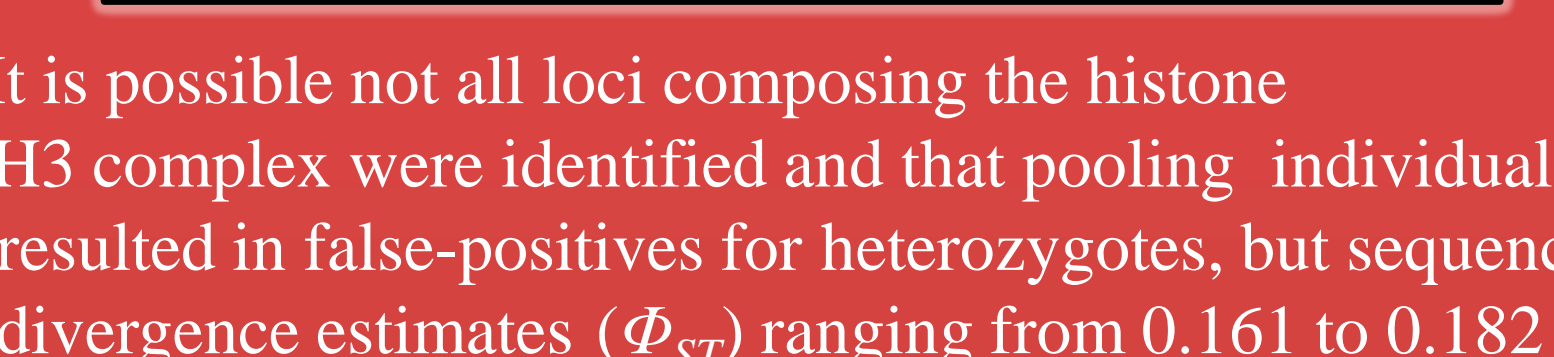

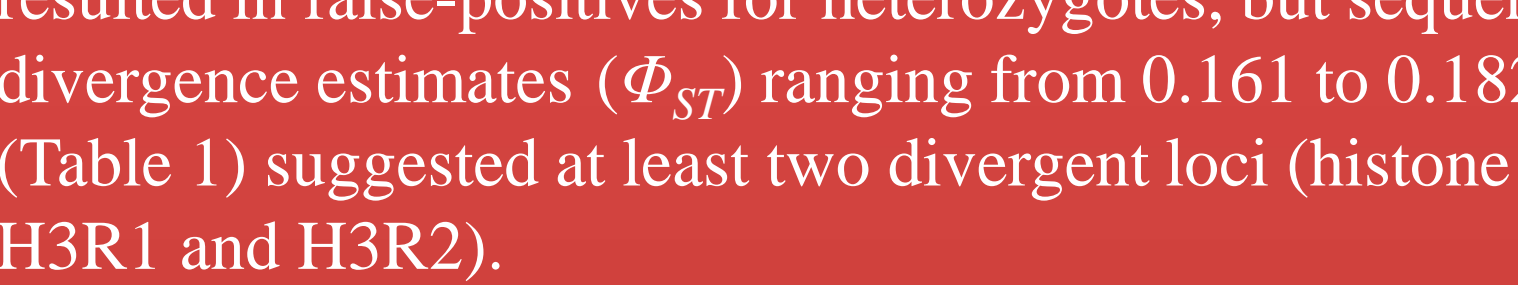

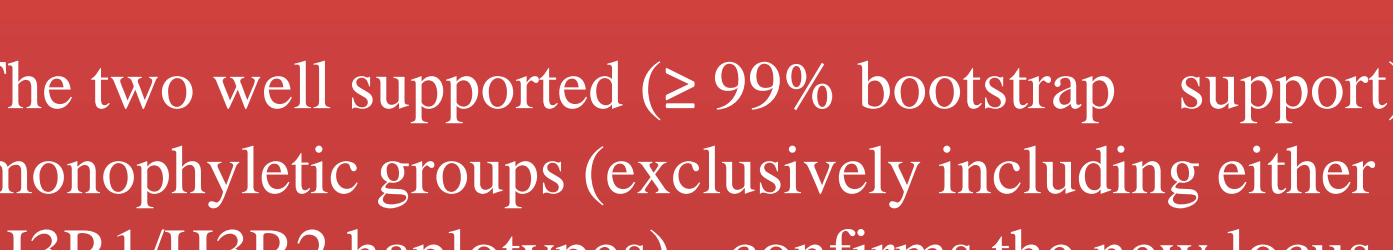

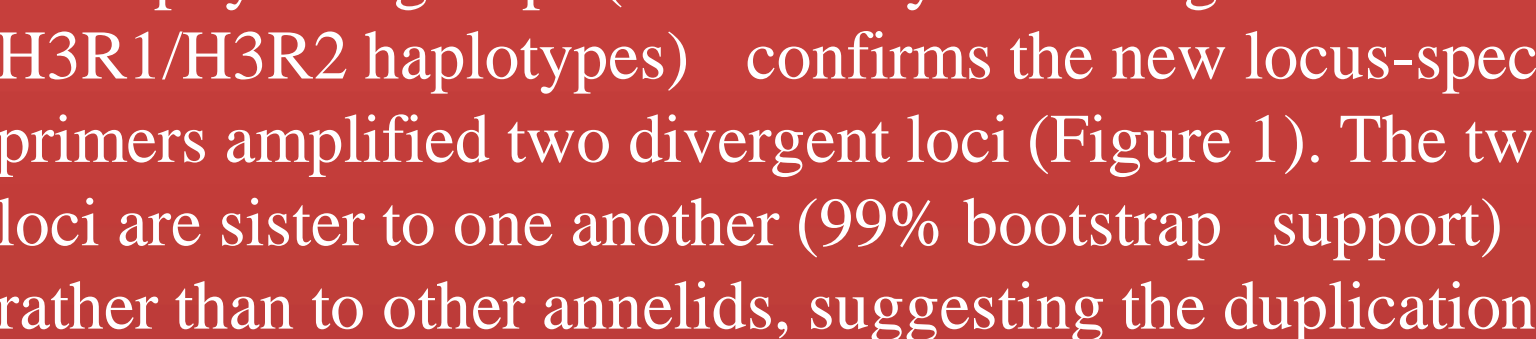

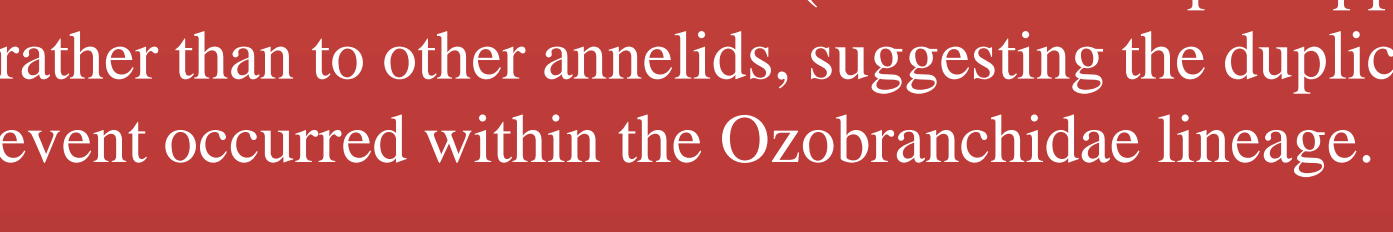

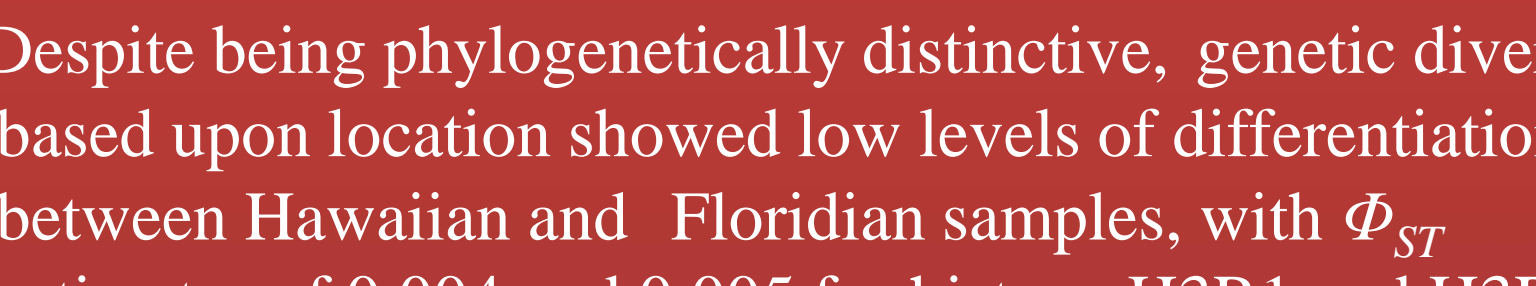

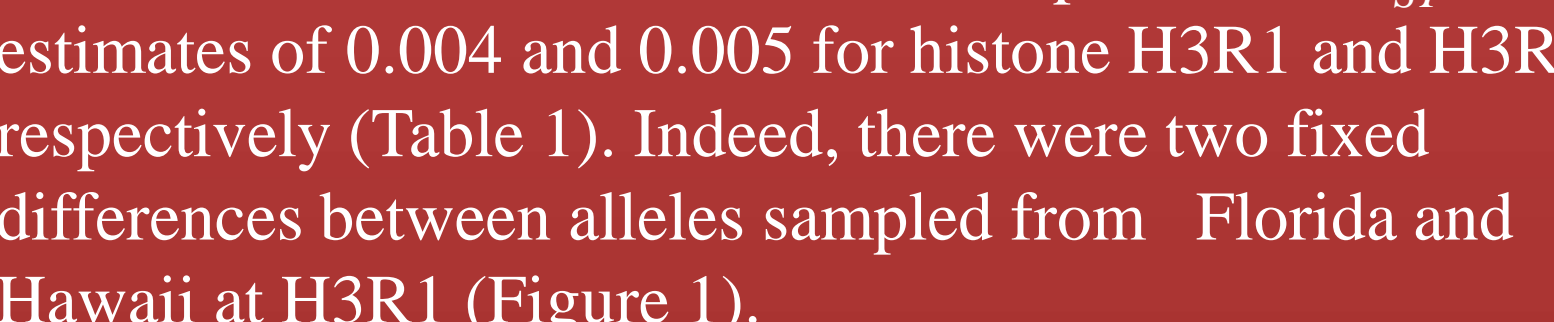
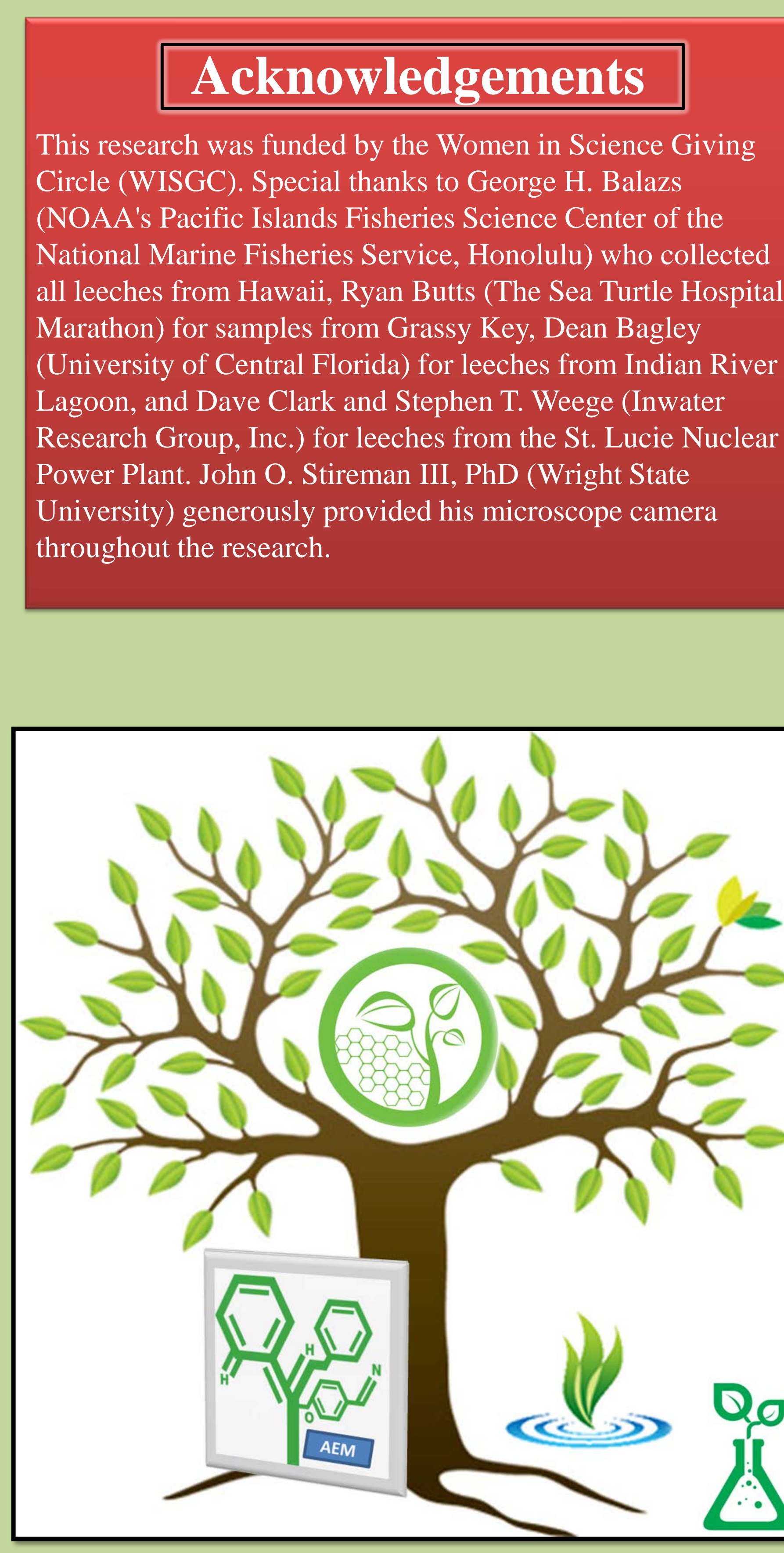

口if

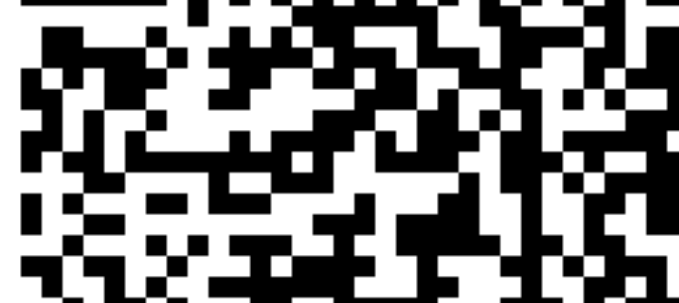

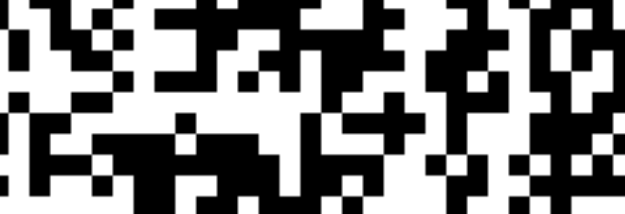

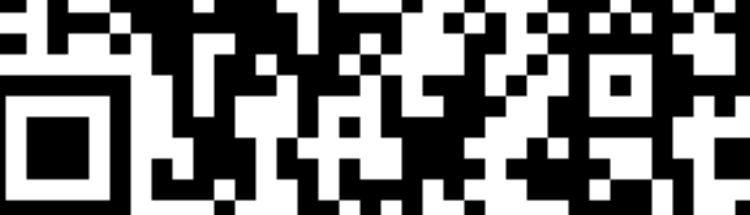

